\title{
Comprehensive genomic analysis contrasting primary colorectal cancer and matched liver metastases: a retrospective study
}

Akio Shiomi ( $\nabla$ a.shiomi@scchr.jp )

Shizuoka Cancer Center https://orcid.org/0000-0001-5657-8686

Masatoshi Kusuhara

Shizuoka Cancer Center Research Institute

Takashi Sugino

Shizuoka Cancer Center

Teiichi Sugiura

Shizuoka Cancer Center

Keiichi Ohshima

Shzuoka Cancer Center Research Institute

Takeshi Nagashima

Shizuoka Cancer Center Research Institute

Kenichi Urakami

Shizuoka Cancer Center Research Institute

Hideyuki Saya

Keio University School of Medicine

Ken Yamaguchi

Shizuoka Cancer Center

Research article

Keywords: colorectal cancer, liver metastasis, gene expression, heterogeneity, microenvironment

Posted Date: July 21 st, 2020

DOI: https://doi.org/10.21203/rs.3.rs-43699/v1

License: (a) (1) This work is licensed under a Creative Commons Attribution 4.0 International License.

Read Full License 


\section{Abstract}

(Background)

Recent studies have revealed that colorectal cancer (CRC) displays intratumor genetic heterogeneity, and the cancer microenvironment play an important role in the proliferation, invasion, and metastasis of CRC.

(Methods)

We performed genomic analysis on 22 paired patients with primary CRC and synchronous colorectal liver metastasis (CRLM) using whole-exome sequencing, cancer gene panels, and microarray gene expression profiling.

In addition, immunohistochemical analysis was used to confirm the protein expression of genes identified as highly expressed in CRLM by DNA microarray analysis.

(Results)

A total of 22 paired patients were enrolled in this study, including $13(59.1 \%)$ colon and 9 (40.9\%) rectal cancer patients. All patients had synchronous liver metastasis and did not have any other extrahepatic metastases.

We identified 11 probes (10 genes) that were highly expressed in CRLM compared to CRC, from 36022 probes obtained from primary CRC, CRLM, and normal liver tissues, using gene expression analysis with DNA microarray.

Of the 11 probes (10 genes), 5 genes classified as encoding "matricellular proteins" (osteopontin, periostin, thrombospondin-2, MGP, and GPNMB) were selected for immunohistochemical analysis.

Osteopontin was strongly expressed in CRLM ( 6 of 22 cases: $27.3 \%$ ) but not in CRC ( 0 of 22: $0 \% ; p=0.02$ ). Periostin also showed strong immunoreactivity in CRLM (17 of 22: 68.2\%) compared to 7 of 22 (31.8\%) in CRC ( $p=0.006)$. Thrombospondin-2 showed strong immunoreactivity both in CRC and CRLM $(54.5 \%$ in $\mathrm{CRC}, 45.5 \%$ in CRLM; $\mathrm{p}=0.55)$. GPNMB and MGP were rarely positive for both CRC and CRLM. A comparison of immunoreactive positive factors for these 5 genes revealed the complexities of gene expression in CRLM. Of the cases, 16 (72.7\%) CRC revealed zero or only one positive immunoreactivity. On the other hand, CRLM revealed more frequent multiple immunoreactivity; 16 cases $(72.7 \%)$ shared 2 or more factors, which was statistically more frequent in CRLM than in CRC $(p=0.007)$.

(Conclusions)

This study revealed the genomic heterogeneity between paired primary CRC and CRLM in terms of cancer cell microenvironment. This finding will lead to new diagnostic and therapeutic targets in the era of genome-guided personalized cancer treatment. 
(Trial registration)

This study was retrospectively registered.

\section{Background}

Colorectal cancer (CRC) is a common malignancy; it has the third highest incidence rate among all cancers and is the second leading cause of cancer-related deaths worldwide [1]. Despite advances in the understanding of the clinicopathological features of CRC as well as improved diagnosis and treatment, mortality from CRC is expected to continue to increase, with approximately 700,000 deaths each year [2]. Unfortunately, at the time of diagnosis, $18.2 \%$ of patients with primary CRC had concurrent distant metastases, with the highest frequency in liver (10.7\%), peritoneum (5.0\%), and lung (1.6\%) [3]. The prognosis of patients with liver metastasis from colorectal cancer (CRLM) has dramatically improved with the availability of new effective cytotoxic and targeted agents as well as aggressive surgical resection. Moreover, recent remarkable improvements in innovative agents have led to an increased response rate in unresectable CRLM. The surgical resection rate after downstaging in initially unresectable CRLM has been reported to be up to $40 \%$ (so called "conversion therapy") [4]. In spite of these developments, the oncological outcomes for patients with CRLM remains unsatisfactory; CRLM recurrence after hepatectomy is common, with a 50\% rate in remnant liver [5-7].

Advances in molecular biology over the past decade have enabled a greater understanding of the development of several kinds of cancers, and a more precise use of innovative targeted therapies. Recent studies have revealed that several cancers display intratumor genetic heterogeneity. Given the intratumor genetic heterogeneity described in several cancers, the metastatic process itself may result in clonal selection in the progression from primary to metastatic disease. The proliferation, invasion, and metastasis of cancer cells are not defined by the nature of the cancer cell itself, but rather by the adaptation of the microenvironment via interactions between the cancer cell and its surrounding tissues $[8,9]$.

Elucidation of intratumor genetic heterogeneity will lead to new diagnostic and therapeutic methods for CRC. Herein, we performed molecular analysis on paired patients with primary CRC and synchronous CRLM, resected at the same institute. In this study, we investigated the molecular characteristics using whole-exome sequencing, cancer gene panels, fusion gene panels and microarray gene expression profiling. A notable feature of this study is that it fully matches all clinicopathological data, as the cases are from the same medical institution. Most previously reported studies used metachronous or unpaired patient samples. Such analysis could be biased by intertumoral heterogeneity and the administration of chemotherapy between the resection of primary CRC and metastatic sites, which might alter the genetic clones. Moreover, the studies used a limited set of biomarkers.

To our knowledge, no other study has analyzed such a completely paired sample of primary CRC and synchronous CRLM using a major complement of exhaustive genetic analysis with next-generation sequencing. 


\section{Methods}

\section{Clinical data}

Surgically resected tumor specimens and corresponding peripheral blood samples were obtained from 22 consecutive patients who underwent both colectomy and hepatectomy for CRC and synchronous CRLM between January 2014 and March 2015. All patients were enrolled in Project HOPE (High-tech Omicsbased Patient Evaluation), a study launched at Shizuoka Cancer Center with the aim of evaluating the biological characteristics of cancer by multiomics-based analyses [10]. The clinicopathological data of patients were retrospectively reviewed. A prospective colorectal database, containing information regarding patient characteristics, preoperative assessment, operative characteristics, postoperative complications, pathological characteristics, and oncological outcomes, maintained at the hospital was used for this retrospective analysis.

\section{Project HOPE (High-tech Omics-based Patient Evaluation)}

In the present study, we evaluated fresh frozen tumor tissues obtained from both primary CRC and CRLM using whole-exome sequencing (WES), cancer gene panel sequencing, fusion gene panel sequencing and microarray-based gene expression profiling (GEP). We also acquired peripheral blood samples from patients and paired them with the corresponding resected tissue samples from the HOPE study. DNA was extracted from blood and tissues by the same method using a QIAamp DNA Blood Kit (QIAGEN, Hilden, Germany), except that tissues were treated with Proteinase K (QIAGEN) [11]. A board-certified pathologist determined that the tumor purity was $>50 \%$. DNA was quantified using Nano-drop (Thermo Fisher Scientific, Waltham, MA, USA) and Qubit 2.0 Fluorometer (Thermo Fisher Scientific).

\section{Ethical considerations}

The research plan of Project HOPE was designed according to the revised Ethical Guidelines for Human Genome/Gene Analysis Research in Japan (http://www.lifescience.mext.go.jp/files/pdf/n1115_01.pdf), and the study protocol was approved by the Institutional Review Board of Shizuoka Cancer Center (approval number \#25-33). Written informed consent was obtained from all participants. This retrospective study was also approved by the same board (approval number \#30-5-30-1-2).

\section{Next-generation sequencing}

The exome library used for WES was prepared using an lon Torrent AmpliSeq RDY Exome Kit (Thermo Fisher Scientific) in accordance with the manufacturer's protocol. A total of $100 \mathrm{ng}$ of DNA was used for target amplification under the following conditions: $99^{\circ} \mathrm{C}$ for $2 \mathrm{~min}$, followed by 10 cycles at $95^{\circ} \mathrm{C}$ for $15 \mathrm{~s}$ and $60^{\circ} \mathrm{C}$ for $16 \mathrm{~min}$, and a final hold at $10^{\circ} \mathrm{C}$. Incorporated primer sequences were partially digested using a proprietary method. Ion Torrent Proton adapters were ligated to the amplicons at $22^{\circ} \mathrm{C}$ for $30 \mathrm{~min}$, followed by $72^{\circ} \mathrm{C}$ for $10 \mathrm{~min}$, and the library was purified with Agencourt Ampure XT beads (Thermo Fisher Scientific). Libraries were quantified using a quantitative polymerase chain reaction (qPCR), and DNA (8 pM) was sequenced using the semiconductor DNA sequencer (Ion Torrent Proton 
Sequencer, Thermo Fisher Scientific) according to the manufacturer's protocol. Matched tumor-normal pair somatic variants were identified using lon Reporter ver. 4.4 software (Thermo Fisher Scientific) [12] after base calling, quality trimming, and mapping to the hg19/GRCh37 reference genome using Torrent Suite software ver. 4.4 (Thermo Fisher Scientific) [13]. In this step, sequence data derived from tumor and blood samples were analyzed separately, and the latter were used as matched controls. In this process, only somatic variants remain after the subtraction of variants from blood data from those acquired from tumor data. In this variant-call workflow, we identified somatic mutations that satisfied the thresholds quality score $\geq 60$ or depth of coverage $\geq 20$. Somatic variants were manually inspected using the Integrative Genomics Viewer [14]. Annotation of detected single nucleotide variants (SNVs) was performed using databases that included germline and somatic variants as follows: COSMIC [15], ClinVar [16], dbSNP [17], UniProt [18] and DrugBank [19].

\section{Comprehensive gene expression analysis using DNA microarray}

Fresh tumor and adjacent normal tissues were soaked in RNAlater reagent (Thermo Fisher Scientific), and total RNA was isolated and purified using a miRNeasy Mini Kit (QIAGEN) according to the manufacturer's protocol. RNA quality was evaluated by RNA integrity number, which was determined using an Agilent 2100 Bioanalyzer (Agilent Technologies, Santa Clara, CA, USA). RNA samples with an RNA integrity number $\geq 6.0$ were used for gene expression analysis. Gene expression analysis was performed on a SurePrint G3 Human Gene Expression $8 \times 60 \mathrm{~K}$ v2 Microarray (Agilent Technologies) using a One-color Low Input Quick Amp Labeling kit (Agilent Technologies) according to the manufacturer's instructions. Data processing to generate raw signal intensity data was performed with GeneSpring version 13.1.1 software (Agilent Technologies). The raw signals were log-transformed and normalized (GeneSpring software, Agilent Technologies), and the difference in the normalized microarray signal intensities (fold change) between the tumor and adjacent normal tissues was calculated.

\section{Immunohistochemical analysis}

Routine pathological diagnosis was achieved using surgically resected tumors fixed in $10 \%$ formalin and embedded in paraffin. Paraffin sections ( $3 \mu \mathrm{m}$ thickness) containing representative histology of the tumor were used for immunohistochemical analysis. Immunohistochemical staining was performed using the Bond III automated stainer and BOND Polymer Refine Detection kit (Leica Biosystems, Bannockburn, IL, USA). The sections were pretreated with Bond Epitope Retrieval Solution for $20 \mathrm{~min}$ at $100{ }^{\circ} \mathrm{C}$ and then reacted with the primary antibodies (Bond Epitope Retrieval Solution 1 for osteopontin and MGP; Bond Epitope Retrieval Solution 2 for periostin, thrombospondin 2, and GPNMB). After reaction with diaminobenzidine chromogen, the sections were counterstained with hematoxylin. The stained sections were independently evaluated by two investigators (A.S. and T.S.) blinded to patient data. Primary antibodies for osteopontin, periostin, thrombospondin-2, and glycoprotein nonmetastatic melanoma protein B (GPNMB) were obtained from Abcam (Cambridge, UK). Primary antibodies for matrix gla protein (MGP) were obtained from Thermo Fisher Scientific. 


\section{Statistical analysis}

Parametric variables are reported as medians (range). For comparisons between two groups, the chisquared and Wilcoxon signed rank test were used. A $p$-value $<0.05$ was considered to be significant. All statistical analyses were performed using IBM SPSS Statistics software for Windows, version 24 (SPSS Inc., Chicago, IL, USA).

\section{Results}

Patients' characteristics

The data set consisted of 22 pairs of primary CRC and CRLM. The patients' characteristics are shown in Table 1. A total of 22 paired patients were enrolled in this study, including $13(59.1 \%)$ colon and $9(40.9 \%)$ rectal cancer patients. Right-sided colon was defined as caecum, ascending, and transverse colon. Leftsided colon was defined as descending and sigmoid colon. All patients had synchronous liver metastasis and did not have any other extrahepatic metastasis. Patients with multiple cancers such as synchronous or metachronous malignancy (within 5 years) other than carcinoma in situ, familial adenomatous polyposis, and appendiceal cancer were excluded. The median number of CRLM of patients was 2 (114). The median size of CRLM was $30(17-110) \mathrm{mm}$. Of the cases, 21 of 22 (95.5\%) received two-stage hepatectomy. The median interval between resection of primary CRC and CRLM was $6(0-15)$ weeks. No patients received adjuvant/neoadjuvant chemo/chemoradiotherapy before and after the resection for primary CRC or hepatectomies for CRLM.

Comparison of tumor mutation burden between primary CRC and CRLM

The tumor mutation burden (TMB), also referred to as "mutation load", represents the number of single nucleotide variations (SNV) per mega base, and has received increasing attention owing to its potential responses to immune checkpoint inhibitors. TMB was determined for the 22 paired samples (Fig. 1). The median TMB in primary CRC was 2.8 (0.9-6.4), whereas it was 3.8 (2.0-6.6) in CRLM. The TMB counts in CRLM tended to be more frequent than those of primary CRC, although there were no statistically significant differences $(p=0.07)$.

Gene mutation profiling

Genomic alterations contributing to tumorigenesis were analyzed using using an analysis pipeline called "Shizuoka Multi-omics Analysis Protocol (SMAP) [10]" developed in-house in primary CRC and CRLM.

Detected genomic alterations are listed in Table 2. In primary CRC, the alteration of TP53, APC, and KRAS was detected in 16 (72.7\%), 14 (63.6\%), and 9 (40.9\%) cases, respectively. In CRLM, the alteration of TP53, APC, and KRAS was detected in 16 (72.7\%), 14 (63.6\%), 9 (40.9\%) cases, respectively. Mutations in KDM6A, FAT3, FBXW7, and LAMA5 were specific to CRLM.

Concordance of mutations in matched pairs of primary CRC and CRLM

The concordance of genomic alterations between paired primary CRC and CRLM varied from 15.8 to $80.6 \%$ in each paired case (median concordance, $49.2 \%$; Fig. 2A). The mutational concordance of KRAS, which is known as an important factor related to tumor metastasis was $100 \%$. On the other hand, the concordance of APC was only $59.1 \%$ (Fig. 2B). 
Gene expression analysis using DNA microarray

To select candidate genes that showed significantly higher expression in CRLM than primary CRC, gene expression was compared using the average expression value of 36022 probes in primary CRC, CRLM, and normal liver tissues (i.e., non-cancerous tissues of liver metastasis cases). First, we selected 1794 probes whose expression was up to 1.5 times higher in CRLM than primary CRC. Second, to remove contamination of normal liver tissues in liver metastasis samples, we compared expression levels in primary CRC with those in non-cancerous liver tissues and selected 198 probes whose expression was higher in primary CRC than normal liver. Third, we chose 20 probes (19 genes) as highly expressed probes in CRLM with a normalized ratio>1.0. Finally, we examined the difference in expression level of these 20 probes in paired samples of CRC and CRLM, and selected 11 probes (10 genes) that showed significantly higher expression in CRLM than CRC (Table 3 and Fig. 3). Figure 4A shows the characteristic expression profiles of the 11 probes in the 22 paired cases. Figure 4B shows the comparison of gene expression between primary CRC and CRLM; all 11 probes showed significantly higher expression in CRLM (Wilcoxon signed rank test, $p<0.001)$.

Immunohistochemical analysis

Immunohistochemical analysis was performed to confirm the protein expression of genes identified by DNA microarray analysis. Among the 10 genes that were highly expressed in CRLM, 5 genes classified as encoding "matricellular proteins", i.e., osteopontin, periostin, thrombospondin-2, MGP, and GPNMB, were selected for this analysis. GPNMB is a type I transmembrane protein with three unique domains: an extracellular domain, a transmembrane domain, and a cytoplasmic domain. The extracellular domain is composed of two regions with distinct properties: the integrin-binding motif and the polycystic kidney disease domain. Thus, we included GPNMB as a matricellular protein in this study. Representative images of immunohistochemical staining are shown in Fig. 5. First, immunoreactive scores were defined independently according to the intensity of staining and the proportion of stained structures. Staining intensity was scored as: 0 , no staining; 1, weak staining; and 2, strong staining. Proportions of stained tumor cells / extracellular matrix (ECM) were classified as: $0, \leq 5 \%$ positive cells; $1,6-25 \%$ positive cells; $2,26-50 \%$ positive cells; and $3, \geq 51 \%$ positive cells. Total scores for intensity and proportion were used to signify the levels of protein expression. A score of $\leq 3$ was considered to represent negative expression, and a score of $\geq 4$ was considered positive expression in this study. Table 4 shows the positive immunoreactivity scores for these 5 proteins.

Osteopontin showed strong immunoreactivity in tumor cells and ECM of CRLM (6 of 22 cases: 27.3\%) compared to no immunoreactivity in primary CRC (0 of 22 cases: $0.0 \%$ ). The immunoreactivity score was significantly higher in CRLM than primary CRC $(p=0.02)$.

Periostin also showed strong immunoreactivity in the ECM of CRLM (17 of 22 cases: $68.2 \%$ ) compared to that of primary CRC (7 of 22 cases: $31.8 \%$ ). Periostin showed no immunoreactivity in the tumor cells of primary CRC and CRLM. Periostin was not expressed with high frequency in primary CRC. However, when expressed, it showed strong immunoreactivity in the peripheral invasive part of primary lesions. 
Thrombospondin-2 showed strong immunoreactivity in tumor cells and ECM of both primary CRC and CRLM, and there were no statistically significant differences $(p=0.55)$.

GPNMB showed weak immunoreactivity in tumor cells but strong immunoreactivity in ECM of both primary CRC and CRLM. These expressions were also observed in macrophages. However, there were no statistically significant differences.

MGP showed strong immunoreactivity in ECM of primary CRC (3 of 22 cases: $13.6 \%$ and CRLM ( 4 of 22 cases: $18.2 \%)$. No statistically significant differences were observed.

Comparison of number of immunoreactive factors

To determine whether differences in the complexity of expression patterns between primary CRC and CRLM can be verified, and to determine genomic heterogeneity, we compared the number of positive immunoreactivities for 22 pairs of primary CRC and CRLM (Table 5). Sixteen cases (72.7\%) of primary CRC showed zero or one positive immunoreactivity, and 6 case $(27.3 \%)$ revealed positivity for 2 or more factors. On the other hand, CRLM revealed more frequent multiple immunoreactivities, 16 cases $(72.7 \%)$ shared 2 or more factors, which was significantly more frequent in CRLM than in primary CRC $(p=0.007)$.

\section{Discussion}

In the present study, we clearly demonstrated genomic heterogeneity between paired primary CRC and CRLM by using a large complement of exhaustive genetic analyses with next-generation sequencing. No other study has analyzed such a completely paired sample of primary CRC and synchronous CRLM. Elucidation of the heterogeneity of microenvironment-related factors on the proliferation, invasion, and metastasis of cancer cells will lead to novel diagnostic and therapeutic targets for CRC in the era of genome-guided personalized cancer treatment.

Recent advances in next-generation sequencing technologies have made it possible to analyze large numbers of sequences, leading to international cancer genome analysis projects such as the Cancer Genome Atlas (TCGA) and the International Cancer Genome Consortium (ICGC). CRC can be classified into four gene expression-based subtypes with distinguishing features, the consensus molecular subtypes (CMSs): CMS1 (microsatellite instability immune, 14\%), CMS2 (canonical, 37\%), CMS3 (metabolic, 13\%), and CMS4 (mesenchymal, 23\%) [20]. This intertumoral heterogeneity has led to the finding that different subtypes of CRC are represented by different genetic makeup, clinical behavior, pathological features, and responses to treatment [21-23].

In addition to the intertumoral heterogeneity mentioned above, intratumoral heterogeneity relates to the genetic heterogeneity between cancer cells within a single tumor. During carcinogenesis, genetic abnormalities accumulate continually, allowing the cells an increased ability to expand and invade. As a result of this continuous process, cancers become genetically heterogeneous, with an indeterminate number of coexisting genomic clones. These clones have different functional characteristics such as the ability to form metastases or respond to chemotherapy. 
Cancer cells survive and proliferate in a microenvironment created by the cells themselves, various stromal cells, and the stromal tissue. The stromal cells that form cancer tissues include fibroblasts, vascular and lymphangial endothelial cells, lymphocytes, and macrophages. Both cells interact with cancer cells, imparting their characteristic biological features on the cancer [24, 25]. Distant metastasis of cancer has also been implicated in interactions between cancer cells and stromal cells in the cancer microenvironment $[8,9]$.

In this study, we determined that many highly expressed genes by DNA microarray analysis were classified as encoding "matricellular proteins", which interact with the ECM. Periostin is a secreted adhesion-related protein expressed in the periosteum and periodontal ligaments, which acts as a critical regulator of the formation and maintenance of bone and teeth, and also plays an important role in tumorigenesis [26]. Recent studies have shown that periostin is highly expressed in various human cancers and have suggested that periostin promotes tumor growth and metastasis [27-29]. Moreover, periostin is reported to enhance the metastatic growth of colon cancer by both preventing stress-induced apoptosis in cancer cells and augmenting endothelial cell survival to promote angiogenesis. The expression level of periostin is reported to be noticeably higher in metastatic tumors than that in the matched primary colon cancer [30].

Osteopontin is a multifunctional ECM phosphorylated glycoprotein (glycol-phosphoprotein) classified into the Small Integrin-Binding Ligand N-linked Glycoprotein (SIBLING) family, and is reported to play an important role in the tumorigenesis, progression and prognosis of various cancers by regulating cellmatrix interactions and cell signaling through binding with integrins and CD44 receptors [31-36]. A pooled data analysis showed that high osteopontin expression was significantly associated with high tumor grade, invasion, lymph node metastasis, tumor distant metastasis and poor survival in CRC [37].

Thrombospondin-2 (THBS2) is a member of the ECM glycoproteins that mediate ECM assembly, cellmatrix interactions, degradation of matrix metalloproteinases (MMP)-2 and MMP-9, and interact with multiple cell receptors and growth factors. The implication of THBS2 expression in CRC has been controversial. Several studies reported an inverse correlation between THBS2 expression level and malignancy grade $[38,39]$. In contrast, resent studies reported that THBS2 expression in CRC was positively correlated with TNM stage and is a strong prognostic indicator [40, 41].

GPNMB gene is reported to be overexpressed in numerous cancers and is often associated with the metastatic phenotype [42-46]. The extracellular domain of GPNMB interacts with integrins to facilitate the recruitment of immune-suppressive and proangiogenic cells to the tumor microenvironment, thereby enhancing tumor migration and invasion [47]. GPNMB expressed in immune cells such as macrophages and dendritic cells $[14,29]$ may impair T-cell activation to down-modulate anti-tumor immune responses [48-50]. However, the role of GPNMB is complex; it appears to have an inhibitory role in some cancers but may promote metastasis in others.

MGP is an ECM protein containing post-translationally modified y-carboxyglutamate residues due to vitamin K-dependent carboxylation. MGP was initially thought to be involved in the inhibition of 
calcification of arteries and cartilage. Further investigation demonstrated that MGP had a wider range of activities, which were dependent of the phosphorylation-carboxylation status, protein expression and variants. Recent studies showed that MGP has a role in tumor angiogenesis by increasing vascular endothelial growth factor gene expression [51-53]. Recently, MGP was reported to be upregulated in a variety of tumors, including ovarian, breast, urogenital and skin cancer. However, in colon and lung cancers, an inverse correlation between MGP expression and survival was observed [54].

In the present study, exhaustive genetic analysis using next-generation sequencing and comparison of immunoreactive factors revealed the complexities of gene expression in CRLM. It is especially notable that CRLM has greater genomic heterogeneity associated with the ECM compared to primary CRC. This result suggests our hypotheses. To proliferate in the liver, which differs environmentally from the original colorectal tissue in which they naturally exist, cancer cells must modify their microenvironment to make it more amenable for survival. A suitable microenvironment cannot be regulated by a single factor; instead, complex factors are involved, especially in metastatic sites. The complexity of intratumor heterogeneity, which we revealed in this study, may be an underlying cause of the resistance to treatment for metastatic disease.

Differences in genomic mutational profiling between primary and metastatic sites have been investigated in several studies [55-57]. However, most studies have used metachronous or unpaired patient samples. Moreover, a limited set of biomarkers was employed to show that metastatic sites have more inherited mutations than primary CRC. These studies have potential biases related to both intra- and intertumoral heterogeneity.

It has been reported that the several kinds of systemic chemotherapy could alter the genomic landscape in several cancers $[58,59]$. Therefore, adjuvant chemotherapy has the potential to alter the genomic mutational profiles of recurrent cancers, so that they would differ from those of primary tumors [60]. Previous analyses evaluating the heterogeneity of metachronous tumors could be biased by the administration of chemotherapy between the resection of primary CRC and metastatic sites, potentially producing alterations in genomic clones $[55,61]$. Our study eliminates this bias since we selected paired samples of synchronous tumors.

This study has two important limitations. First, the study included a relatively small number of patients. We plan to continue our analysis using an increased number of cases in the future. Next, although the gene expression of thrombospondin-2, GPNMB, and MGP in CRLM was more frequent than in primary CRC according to the DNA microarray analysis, the immunohistochemical analysis revealed no differences in expression. We suggest that the discrepancy between the tissue regions analyzed by DNA microarray and those subjected to immunohistochemical analysis led to this result. The relatively low immunoreactivity scores of GPNMB and MGP may be attributed to the timing of degradation and washout of these proteins from the tissue [53].

There are three future perspectives from this study. First, we also obtained data of surgically resected tumor specimens and corresponding peripheral blood samples not only for CRLM, but also pulmonary 
metastasis, peritoneal metastasis, ovarian metastasis and so on, through WES, cancer gene panel sequencing, fusion gene panel sequencing and microarray-based GEP under the framework of "project HOPE". Thus, we will be able to perform further investigations using these samples. Second, studied of circulating tumor cells (liquid biopsy) may be useful in establishing early CRLM diagnosis. Additionally, it may lead to better predictive biomarkers to identify patients who might benefit from adjuvant chemotherapy. Third, the genes that were overexpressed in this study have the potential to be new therapeutic targets. For example, administration of anti-periostin antibody significantly inhibited the growth of primary tumors as well as metastatic tumors in a murine model of breast cancer [26]. Osteopontin-inhibition is also reported to be a favorable therapeutic approach to metastatic disease [6265]. An antibody-drug conjugate targeting GPNMB, called glembatumumab vedotin (CDX-011), is currently in clinical studies for various cancers [66].

\section{Conclusions}

In conclusion, we revealed the genomic heterogeneity between paired primary CRC and CRLM in terms of the microenvironment on the proliferation, invasion, and metastasis of cancer cells. This will lead to new diagnostic and therapeutic targets for CRC in the era of genome-guided personalized cancer treatment.

\section{Abbreviations}

CRC

colorectal cancer

CRLM

colorectal liver metastasis

Project HOPE

High-tech Omics-based Patient Evaluation

WES

whole-exome sequencing

GEP

gene expression profiling

SNV

single nucleotide variants

GPNMB

glycoprotein nonmetastatic melanoma protein $B$

MGP

matrix gla protein

THBS2

thrombospondin-2

TMB

tumor mutation burden

SMAP 
Shizuoka Multi-omics Analysis Protocol

ECM

extracellular matrix

CMS

consensus molecular subtypes

TCGA

the Cancer Genome Atlas

ICGC

the International Cancer Genome Consortium

SIBLING

small integrin-binding ligand $\mathrm{N}$-linked glycoprotein

MMP

matrix metalloproteinases

\section{Declarations}

\section{Ethics approval and consent to participate}

The research plan of Project HOPE was designed according to the revised Ethical Guidelines for Human Genome/Gene Analysis Research in Japan (http://www.lifescience.mext.go.jp/files/pdf/n1115_01.pdf), and the study protocol was approved by the Institutional Review Board of Shizuoka Cancer Center (approval number \#25-33).

Written informed consent was obtained from all participants.

This retrospective study was also approved by the same board (approval number \#30-5-30-1-2).

\section{Consent for publication}

Consent for publication were obtained from all participants.

\section{Availability of data and materials}

The datasets used and analysed during the current study are available from the corresponding author on reasonable request.

\section{Competing interests}

The authors declare that they have no competing interest.

\section{Funding}

We obtained no funding for this study. 


\section{Authors' contributions}

Akio Shiomi, Masatoshi Kusuhara and Takashi Sugino designed the study.

Akio Shiomi and Teiichi Sugiura enrolled patients.

Akio Shiomi, Masatoshi Kusuhara, Takashi Sugino, and Takeshi Nagashima analysed and interpreted the data.

Akio Shiomi drafted the manuscript.

All authors reviewed and revised the paper and approved the submitted version.

\section{Acknowledgements}

We thank all the staff of the Shizuoka Cancer Center Hospital for assistance in sample preparation and the members of the Shizuoka Cancer Center Research Institute for interesting discussions.

\section{References}

1. DeSantis CE, Lin CC, Mariotto AB, Siegel RL, Stein KD, Kramer JL, Alteri R, Robbins AS, Jemal A. Cancer treatment and survivorship statistics, 2014. CA Cancer J Clin. 2014;64(4):252-71.

2. Bray F, Ferlay J, Soerjomataram I, Siegel RL, Torre LA, Jemal A. Global cancer statistics 2018: GLOBOCAN estimates of incidence and mortality worldwide for 36 cancers in 185 countries. CA Cancer J Clin. 2018;68(6):394-424.

3. Hashiguchi Y, Muro K, Saito Y, Ito Y, Ajioka Y, Hamaguchi T, Hasegawa K, Hotta K, Ishida H, Ishiguro M, et al. Japanese Society for Cancer of the Colon and Rectum (JSCCR) guidelines 2019 for the treatment of colorectal cancer. Int J Clin Oncol. 2020;25(1):1-42.

4. Folprecht G, Gruenberger T, Bechstein WO, Raab HR, Lordick F, Hartmann JT, Lang H, Frilling A, Stoehlmacher J, Weitz $\mathrm{J}$, et al. Tumour response and secondary resectability of colorectal liver metastases following neoadjuvant chemotherapy with cetuximab: the CELIM randomised phase 2 trial. Lancet Oncol. 2010;11(1):38-47.

5. Majeed AW. Surgery for colorectal liver metastases with hepatic lymph node involvement: a systematic review. Br J Surg. 2000;87(12):1737.

6. Martin LW, Warren RS. Current management of colorectal liver metastases. Surg Oncol Clin N Am. 2000;9(4):853-76. discussion 877 - 858.

7. Penna C, Nordlinger B. Colorectal metastasis (liver and lung). Surg Clin North Am. 2002;82(5):107590. $x$-xi.

8. Fidler IJ, Kripke ML. Metastasis results from preexisting variant cells within a malignant tumor. Science. 1977;197(4306):893-5. 
9. Futakuchi M, Nannuru KC, Varney ML, Sadanandam A, Nakao K, Asai K, Shirai T, Sato SY, Singh RK. Transforming growth factor-beta signaling at the tumor-bone interface promotes mammary tumor growth and osteoclast activation. Cancer Sci. 2009;100(1):71-81.

10. Nagashima T, Yamaguchi K, Urakami K, Shimoda Y, Ohnami S, Ohshima K, Tanabe T, Naruoka A, Kamada F, Serizawa M, et al. Japanese version of The Cancer Genome Atlas, JCGA, established using fresh frozen tumors obtained from 5143 cancer patients. Cancer Sci. 2020;111(2):687-99.

11. Scherczinger CA, Bourke MT, Ladd C, Lee HC. DNA extraction from liquid blood using QIAamp. J Forensic Sci. 1997;42(5):893-6.

12. Ion Reporter Software User Guide: Tumor-Normal pair workflow (URL: https://ionreporter.thermofisher.com/ionreporter/ html).

13. Torrent. Suite v4.4.3 User and Admin Guide (URL: https://ioncommunity.thermofisher.com/docs/DOC-9305).

14. Robinson JT, Thorvaldsdottir H, Winckler W, Guttman M, Lander ES, Getz G, Mesirov JP. Integrative genomics viewer. Nat Biotechnol. 2011;29(1):24-6.

15. Kotelnikova EA, Pyatnitskiy M, Paleeva A, Kremenetskaya O, Vinogradov D. Practical aspects of NGSbased pathways analysis for personalized cancer science and medicine. Oncotarget. 2016;7(32):52493-516.

16. Landrum MJ, Lee JM, Riley GR, Jang W, Rubinstein WS, Church DM, Maglott DR. ClinVar: public archive of relationships among sequence variation and human phenotype. Nucleic Acids Res. 2014;42(Database issue):D980-5.

17. Sherry ST, Ward MH, Kholodov M, Baker J, Phan L, Smigielski EM, Sirotkin K. dbSNP: the NCBI database of genetic variation. Nucleic Acids Res. 2001;29(1):308-11.

18. UniProt: a hub for protein information. Nucleic Acids Res 2015, 43(Database issue):D204-212.

19. Wishart DS, Knox C, Guo AC, Shrivastava S, Hassanali M, Stothard P, Chang Z, Woolsey J. DrugBank: a comprehensive resource for in silico drug discovery and exploration. Nucleic Acids Res. 2006;34(Database issue):D668-72.

20. Guinney J, Dienstmann R, Wang X, de Reynies A, Schlicker A, Soneson C, Marisa L, Roepman P, Nyamundanda G, Angelino P, et al. The consensus molecular subtypes of colorectal cancer. Nat Med. 2015;21(11):1350-6.

21. Sadanandam A, Lyssiotis CA, Homicsko K, Collisson EA, Gibb WJ, Wullschleger S, Ostos LC, Lannon WA, Grotzinger C, Del Rio $M$, et al. A colorectal cancer classification system that associates cellular phenotype and responses to therapy. Nat Med. 2013;19(5):619-25.

22. Le DT, Uram JN, Wang H, Bartlett BR, Kemberling H, Eyring AD, Skora AD, Luber BS, Azad NS, Laheru D, et al. PD-1 Blockade in Tumors with Mismatch-Repair Deficiency. N Engl J Med. 2015;372(26):2509-20.

23. Le DT, Durham JN, Smith KN, Wang H, Bartlett BR, Aulakh LK, Lu S, Kemberling H, Wilt C, Luber BS, et al. Mismatch repair deficiency predicts response of solid tumors to PD-1 blockade. Science. 2017;357(6349):409-13. 
24. Polanska UM, Orimo A. Carcinoma-associated fibroblasts: non-neoplastic tumour-promoting mesenchymal cells. J Cell Physiol. 2013;228(8):1651-7.

25. Ishii G, Ochiai A, Neri S. Phenotypic and functional heterogeneity of cancer-associated fibroblast within the tumor microenvironment. Adv Drug Deliv Rev. 2016;99(Pt B):186-96.

26. Kyutoku M, Taniyama Y, Katsuragi N, Shimizu H, Kunugiza Y, lekushi K, Koibuchi N, Sanada F, Oshita $\mathrm{Y}$, Morishita R. Role of periostin in cancer progression and metastasis: inhibition of breast cancer progression and metastasis by anti-periostin antibody in a murine model. Int $\mathrm{J}$ Mol Med. 2011;28(2):181-6.

27. Erkan M, Kleeff J, Gorbachevski A, Reiser C, Mitkus T, Esposito I, Giese T, Büchler MW, Giese NA, Friess $\mathrm{H}$. Periostin creates a tumor-supportive microenvironment in the pancreas by sustaining fibrogenic stellate cell activity. Gastroenterology. 2007;132(4):1447-64.

28. Kudo Y, Ogawa I, Kitajima S, Kitagawa M, Kawai H, Gaffney PM, Miyauchi M, Takata T. Periostin promotes invasion and anchorage-independent growth in the metastatic process of head and neck cancer. Cancer Res. 2006;66(14):6928-35.

29. Puglisi F, Puppin C, Pegolo E, Andreetta C, Pascoletti G, D'Aurizio F, Pandolfi M, Fasola G, Piga A, Damante G, et al. Expression of periostin in human breast cancer. J Clin Pathol. 2008;61(4):494-8.

30. Moniuszko T, Wincewicz A, Koda M, Domysławska I, Sulkowski S. Role of periostin in esophageal, gastric and colon cancer. Oncol Lett. 2016;12(2):783-7.

31. Sodek J, Ganss B, McKee MD. Osteopontin. Crit Rev Oral Biol Med. 2000;11(3):279-303.

32. Zhang J, Takahashi K, Takahashi F, Shimizu K, Ohshita F, Kameda Y, Maeda K, Nishio K, Fukuchi Y. Differential osteopontin expression in lung cancer. Cancer Lett. 2001;171(2):215-22.

33. Song G, Cai QF, Mao YB, Ming YL, Bao SD, Ouyang GL. Osteopontin promotes ovarian cancer progression and cell survival and increases HIF-1alpha expression through the PI3-K/Akt pathway. Cancer Sci. 2008;99(10):1901-7.

34. Kim JY, Bae BN, Kim KS, Shin E, Park K. Osteopontin, CD44, and NFkappaB expression in gastric adenocarcinoma. Cancer Res Treat. 2009;41(1):29-35.

35. Likui W, Hong W, Shuwen Z. Clinical significance of the upregulated osteopontin mRNA expression in human colorectal cancer. J Gastrointest Surg. 2010;14(1):74-81.

36. Bramwell VH, Tuck AB, Chapman JA, Anborgh PH, Postenka CO, Al-Katib W, Shepherd LE, Han L, Wilson CF, Pritchard Kl, et al. Assessment of osteopontin in early breast cancer: correlative study in a randomised clinical trial. Breast Cancer Res. 2014;16(1):R8.

37. Zhao M, Liang F, Zhang B, Yan W, Zhang J: The impact of osteopontin on prognosis and clinicopathology of colorectal cancer patients: a systematic meta-analysis. Sci Rep 2015, 5:12713.

38. Tokunaga T, Nakamura M, Oshika Y, Abe Y, Ozeki Y, Fukushima Y, Hatanaka H, Sadahiro S, Kijima H, Tsuchida T, et al. Thrombospondin 2 expression is correlated with inhibition of angiogenesis and metastasis of colon cancer. Br J Cancer. 1999;79(2):354-9. 
39. de Fraipont F, Nicholson AC, Feige JJ, Van Meir EG. Thrombospondins and tumor angiogenesis. Trends Mol Med. 2001;7(9):401-7.

40. Kim H, Watkinson J, Varadan V, Anastassiou D. Multi-cancer computational analysis reveals invasion-associated variant of desmoplastic reaction involving INHBA, THBS2 and COL11A1. BMC Med Genomics. 2010;3:51.

41. Tian Q, Liu Y, Zhang Y, Song Z, Yang J, Zhang J, Guo T, Gao W, Dai F, He C. THBS2 is a biomarker for AJCC stages and a strong prognostic indicator in colorectal cancer. J buon. 2018;23(5):1331-6.

42. Rich JN, Shi Q, Hjelmeland M, Cummings TJ, Kuan CT, Bigner DD, Counter CM, Wang XF. Bone-related genes expressed in advanced malignancies induce invasion and metastasis in a genetically defined human cancer model. J Biol Chem. 2003;278(18):15951-7.

43. Kuan CT, Wakiya K, Dowell JM, Herndon JE 2nd, Reardon DA, Graner MW, Riggins GJ, Wikstrand CJ, Bigner DD. Glycoprotein nonmetastatic melanoma protein B, a potential molecular therapeutic target in patients with glioblastoma multiforme. Clin Cancer Res. 2006;12(7 Pt 1):1970-82.

44. Rose AA, Pepin F, Russo C, Abou Khalil JE, Hallett M, Siegel PM. Osteoactivin promotes breast cancer metastasis to bone. Mol Cancer Res. 2007;5(10):1001-14.

45. Rose AA, Annis MG, Dong Z, Pepin F, Hallett M, Park M, Siegel PM. ADAM10 releases a soluble form of the GPNMB/Osteoactivin extracellular domain with angiogenic properties. PLoS One. 2010;5(8):e12093.

46. Rose AA, Grosset AA, Dong Z, Russo C, Macdonald PA, Bertos NR, St-Pierre Y, Simantov R, Hallett M, Park $\mathrm{M}$, et al. Glycoprotein nonmetastatic $B$ is an independent prognostic indicator of recurrence and a novel therapeutic target in breast cancer. Clin Cancer Res. 2010;16(7):2147-56.

47. Taya M, Hammes SR. Glycoprotein Non-Metastatic Melanoma Protein B (GPNMB) and Cancer: A Novel Potential Therapeutic Target. Steroids. 2018;133:102-7.

48. Zhou LT, Liu FY, Li Y, Peng YM, Liu YH, Li J. Gpnmb/osteoactivin, an attractive target in cancer immunotherapy. Neoplasma. 2012;59(1):1-5.

49. Selim AA. Osteoactivin bioinformatic analysis: prediction of novel functions, structural features, and modes of action. Med Sci Monit. 2009;15(2):Mt19-33.

50. Singh M, Del Carpio-Cano F, Belcher JY, Crawford K, Frara N, Owen TA, Popoff SN, Safadi FF. Functional roles of osteoactivin in normal and disease processes. Crit Rev Eukaryot Gene Expr. 2010;20(4):341-57.

51. Mertsch S, Schurgers LJ, Weber K, Paulus W, Senner V. Matrix gla protein (MGP): an overexpressed and migration-promoting mesenchymal component in glioblastoma. BMC Cancer. 2009;9:302.

52. Kuzontkoski PM, Mulligan-Kehoe MJ, Harris BT, Israel MA. Inhibitor of DNA binding-4 promotes angiogenesis and growth of glioblastoma multiforme by elevating matrix GLA levels. Oncogene. 2010;29(26):3793-802.

53. Gheorghe SR, Craciun AM. Matrix Gla protein in tumoral pathology. Clujul Med. 2016;89(3):319-21. 
54. Caiado H, Conceicao N, Tiago D, Marreiros A, Vicente S, Enriquez JL, Vaz AM, Antunes A, Guerreiro H, Caldeira P, et al. Evaluation of MGP gene expression in colorectal cancer. Gene. 2020;723:144120.

55. Hope NR, Murray GI. The expression profile of RNA-binding proteins in primary and metastatic colorectal cancer: relationship of heterogeneous nuclear ribonucleoproteins with prognosis. Hum Pathol. 2011;42(3):393-402.

56. Vakiani E, Janakiraman M, Shen R, Sinha R, Zeng Z, Shia J, Cercek A, Kemeny N, D'Angelica M, Viale $\mathrm{A}$, et al. Comparative genomic analysis of primary versus metastatic colorectal carcinomas. J Clin Oncol. 2012;30(24):2956-62.

57. Schrijver W, Selenica P, Lee JY, Ng CKY, Burke KA, Piscuoglio S, Berman SH, Reis-Filho JS, Weigelt B, van Diest PJ, et al. Mutation Profiling of Key Cancer Genes in Primary Breast Cancers and Their Distant Metastases. Cancer Res. 2018;78(12):3112-21.

58. Ding L, Ley TJ, Larson DE, Miller CA, Koboldt DC, Welch JS, Ritchey JK, Young MA, Lamprecht T, McLellan MD, et al. Clonal evolution in relapsed acute myeloid leukaemia revealed by whole-genome sequencing. Nature. 2012;481(7382):506-10.

59. Johnson BE, Mazor T, Hong C, Barnes M, Aihara K, McLean CY, Fouse SD, Yamamoto S, Ueda H, Tatsuno K, et al. Mutational analysis reveals the origin and therapy-driven evolution of recurrent glioma. Science. 2014;343(6167):189-93.

60. Harada K, Okamoto W, Mimaki S, Kawamoto Y, Bando H, Yamashita R, Yuki S, Yoshino T, Komatsu Y, Ohtsu A, et al. Comparative sequence analysis of patient-matched primary colorectal cancer, metastatic, and recurrent metastatic tumors after adjuvant FOLFOX chemotherapy. BMC Cancer. 2019;19(1):255.

61. Gagniere J, Dupre A, Gholami SS, Pezet D, Boerner T, Gonen M, Kingham TP, Allen PJ, Balachandran VP, De Matteo RP, et al. Is Hepatectomy Justified for BRAF Mutant Colorectal Liver Metastases?: A Multi-institutional Analysis of 1497 Patients. Ann Surg. 2020;271(1):147-54.

62. Wu Y, Denhardt DT, Rittling SR. Osteopontin is required for full expression of the transformed phenotype by the ras oncogene. Br J Cancer. 2000;83(2):156-63.

63. Nemoto H, Rittling SR, Yoshitake H, Furuya K, Amagasa T, Tsuji K, Nifuji A, Denhardt DT, Noda M. Osteopontin deficiency reduces experimental tumor cell metastasis to bone and soft tissues. $J$ Bone Miner Res. 2001;16(4):652-9.

64. Wu XL, Lin KJ, Bai AP, Wang WX, Meng XK, Su XL, Hou MX, Dong PD, Zhang JJ, Wang ZY, et al. Osteopontin knockdown suppresses the growth and angiogenesis of colon cancer cells. World $\mathrm{J}$ Gastroenterol. 2014;20(30):10440-8.

65. Wei R, Wong JPC, Kwok HF. Osteopontin - a promising biomarker for cancer therapy. J Cancer. 2017;8(12):2173-83.

66. Rose AAN, Biondini M, Curiel R, Siegel PM. Targeting GPNMB with glembatumumab vedotin: Current developments and future opportunities for the treatment of cancer. Pharmacol Ther. 2017;179:12741. 


\section{Tables}

Page $18 / 28$ 
Table 1. Patient characteristics $(n=22)$

Gender

Male

12

Female

Age (year)

$64.5(27-86)$

$<50$

$\geq 50$

Primary tumor site

Colon

Right side

Left side

Rectum

CEA (ng/ml)

$24.7(1.8-1421)$

$>5.0$

Histological type of primary site

Differentiated 21

Undifferentiated 1

pT stage

pT1 0

pT2 1

pT3 9

$\begin{array}{ll}\text { pT4 } & 12\end{array}$

$\mathrm{pN}$ stage

$\begin{array}{lr}\text { pN0 } & 3 \\ \text { pN1 } & 9 \\ \text { pN2 } & 10\end{array}$

Synchronous presentation of CRLM

Absent 
Lymphatic invasion
Absent
12
Present

Venous invasion

$\begin{array}{lr}\text { Absent } & 4 \\ \text { Present } & 18\end{array}$

Median number of CRLM

$2(1-14)$

Largest size of CRLM (cm)

$30(17-110)$

Multiple CRLM

$\begin{array}{lr}\text { Absent } & 9 \\ \text { Present } & 13\end{array}$

Extrahepatic disease

Absent 22

Present 0

Neoadjuvant chemo(radio)therapy

Absent 22

Present 0

Values for Age, CEA, and Largest size of CRLM are provided as the median (range).

CEA: carcinoembryonic antigen, CRLM: colorectal liver metastasis 
Table 2. Gene mutation profiling of primary CRC and CRLM

\begin{tabular}{lclc}
\hline CRC & $\mathrm{n}$ & CRLM & $\mathrm{n}$ \\
\hline TP53 & 16 & TP53 & 16 \\
APC & 14 & APC & 14 \\
KRAS & 9 & KRAS & 9 \\
CSMD3 & 5 & CSMD3 & 5 \\
EPHA5 & 3 & EPHA5 & 4 \\
FAT4 & 3 & FAT4 & 4 \\
FBXW7 & 3 & KDM6A & 4 \\
KMT2D & 3 & FAT3 & 3 \\
PIK3CA & 3 & FBXW7 & 3 \\
TERT & 3 & LAMA5 & 3 \\
TSHZ2 & 3 & TERT & 3 \\
& & TSHZ2 & 3 \\
\hline
\end{tabular}

Bold letters indicate gene mutations found only in liver metastases

CRC: colorectal cancer CRLM: colorectal liver metastasis 
Table 3. Gene expression analysis using DNA microarray

\begin{tabular}{|c|c|c|c|c|c|}
\hline $\begin{array}{l}\text { Gene } \\
\text { Symbol }\end{array}$ & Gene name & Location & $\begin{array}{l}\text { Variance } \\
\text { F value }\end{array}$ & $\begin{array}{l}\text { Variance } \\
\text { पvalue }\end{array}$ & $\begin{array}{l}\text { Bonferroni } \\
<0.05 / 20=0.0025\end{array}$ \\
\hline SPP1 & Osteopontin & ECM & 55.8088 & $\square 0.0001$ & 0.0025 \\
\hline TIMP1 & $\begin{array}{l}\text { tissue inhibitor of } \\
\text { metalloproteinase } \\
1\end{array}$ & secreted & 48.9451 & $\square 0.0001$ & 0.0025 \\
\hline THBS2 & $\begin{array}{l}\text { Thrombospondin- } \\
2\end{array}$ & ECM & 25.8758 & $\square 0.0001$ & 0.0025 \\
\hline POSTN & periostin & ECM & 24.8512 & $\square 0.0001$ & 0.0025 \\
\hline GPNMB & $\begin{array}{l}\text { glycoprotein } \\
\text { nonmetastatic } \\
\text { melanoma } \\
\text { protein B }\end{array}$ & $\begin{array}{l}\text { membrane } \\
\text { (with } \\
\text { ECM } \\
\text { domain) }\end{array}$ & 24.5809 & $\square 0.0001$ & 0.0025 \\
\hline MGP_2 & $\begin{array}{l}\text { Matrix Gla } \\
\text { protein }\end{array}$ & ECM & 19.8335 & $\square 0.0001$ & 0.0025 \\
\hline MGP & $\begin{array}{l}\text { Matrix Gla } \\
\text { protein }\end{array}$ & ECM & 19.1511 & $\square 0.0001$ & 0.0025 \\
\hline COL10A1 & $\begin{array}{l}\text { Collagen type X } \\
\text { alpha } 1 \text { chain }\end{array}$ & ECM & 13.0898 & 0.0008 & 0.0025 \\
\hline CCDC80 & $\begin{array}{l}\text { Coiled-coil } \\
\text { domain } \\
\text { containing } 80\end{array}$ & cytosol & 12.5409 & 0.001 & 0.0025 \\
\hline CCDC146 & $\begin{array}{l}\text { Coiled-coil } \\
\text { domain } \\
\text { containing } 146\end{array}$ & nucleus & 11.3416 & 0.0016 & 0.0025 \\
\hline CCL18 & $\begin{array}{l}\text { Chemokine (C-C } \\
\text { motif) ligand } 18\end{array}$ & secreted & 10.4601 & 0.0024 & 0.0025 \\
\hline
\end{tabular}


Table 4A. Expression status of each factor by immunostaining

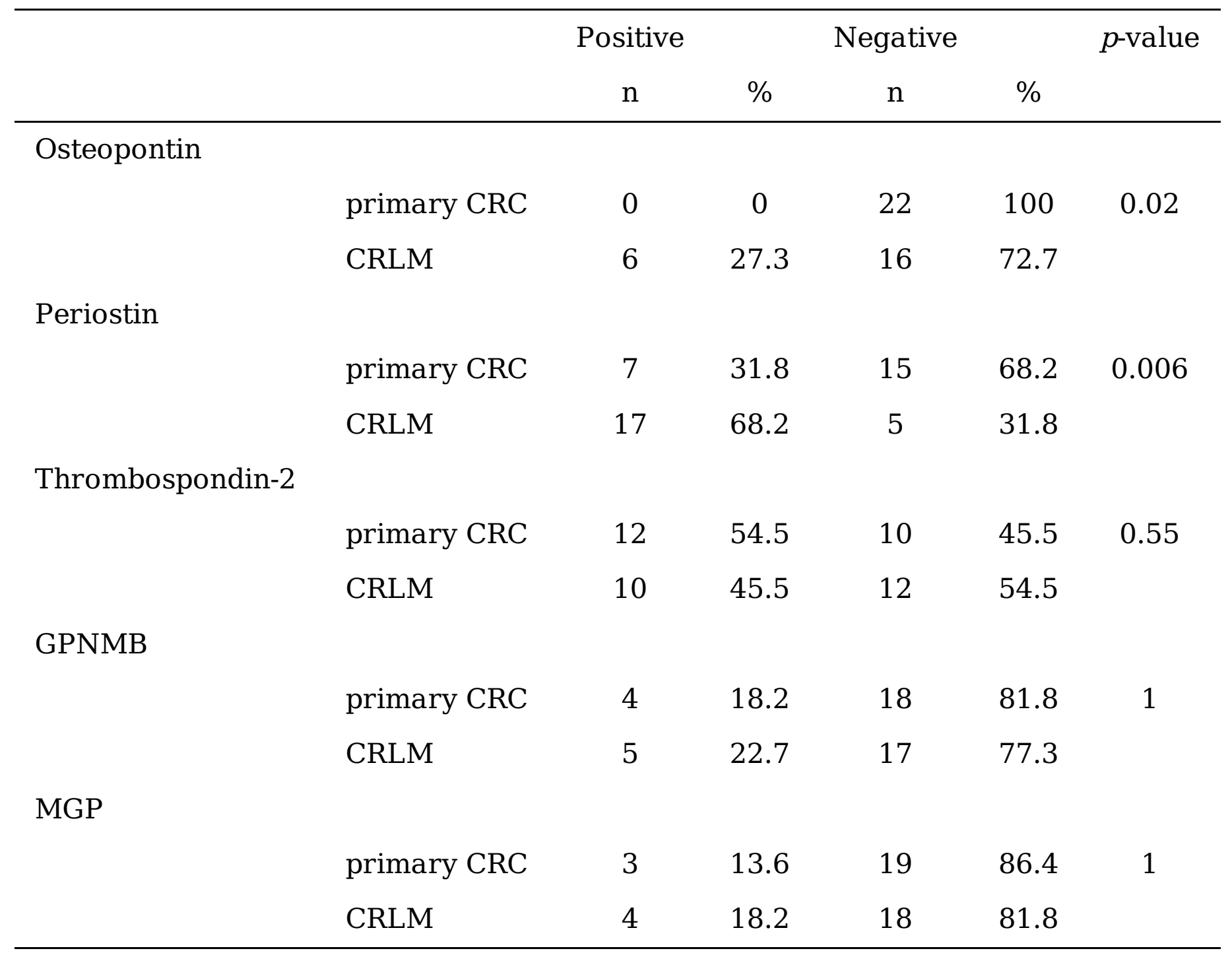

CRC: colorectal cancer CRLM: colorectal liver metastasis 
Table 5. Comparison of number of positive immunoreactivities between primary CRC and CRLM

Primary CRC $(\mathrm{n}=22) \quad$ CRLM $(\mathrm{n}=22) \quad p$-value

\begin{tabular}{lccc}
0 or 1 factor & $16(72.7 \%)$ & $6(27.3 \%)$ & 0.007 \\
2 or more factors & $6(27.3 \%)$ & $16(72.7 \%)$ & \\
\hline
\end{tabular}

CRC: colorectal cancer CRLM: colorectal liver metastasis

\section{Figures}

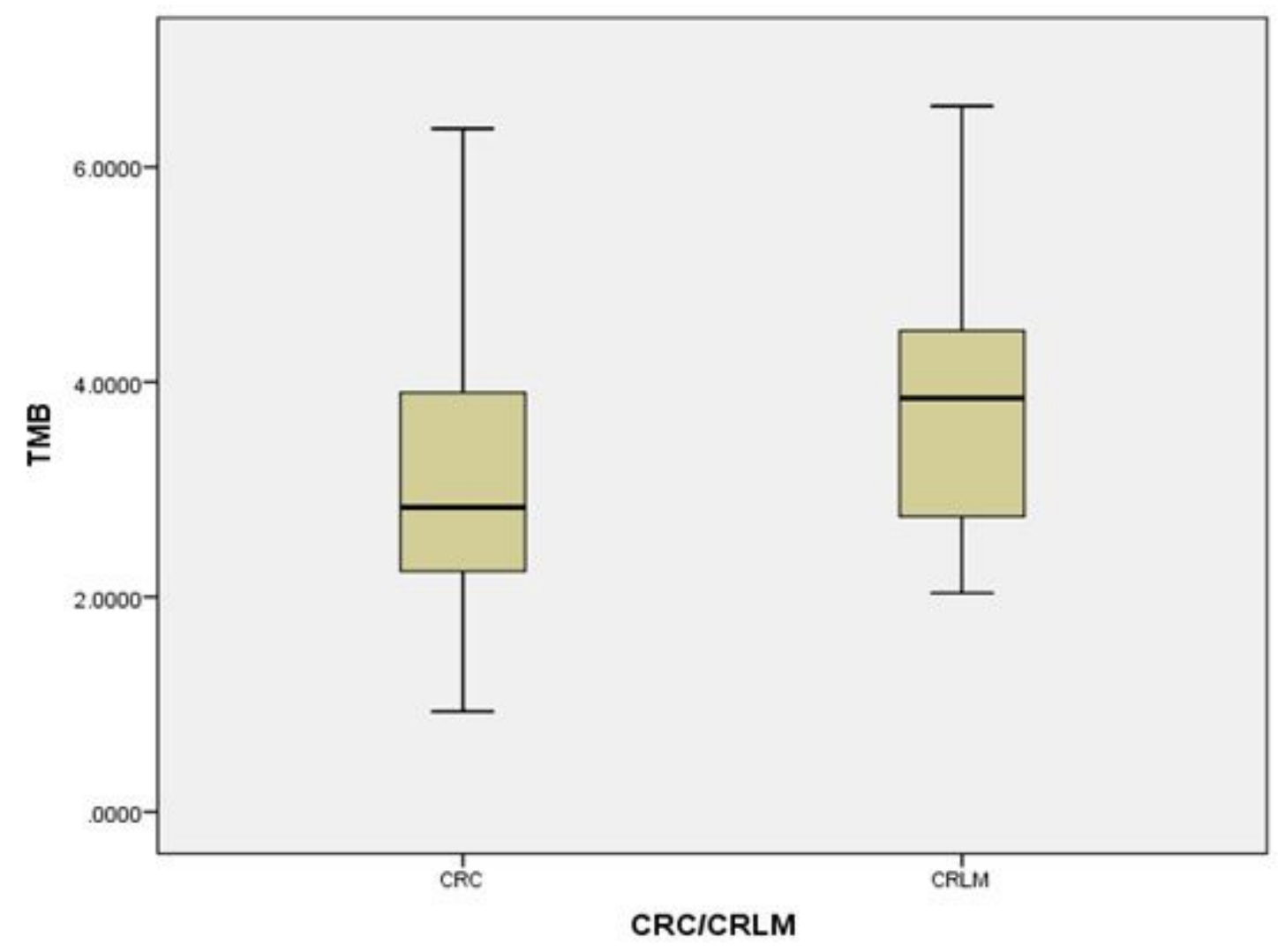

Figure 1

Comparison of tumor mutation burden between primary CRC and CRLM 


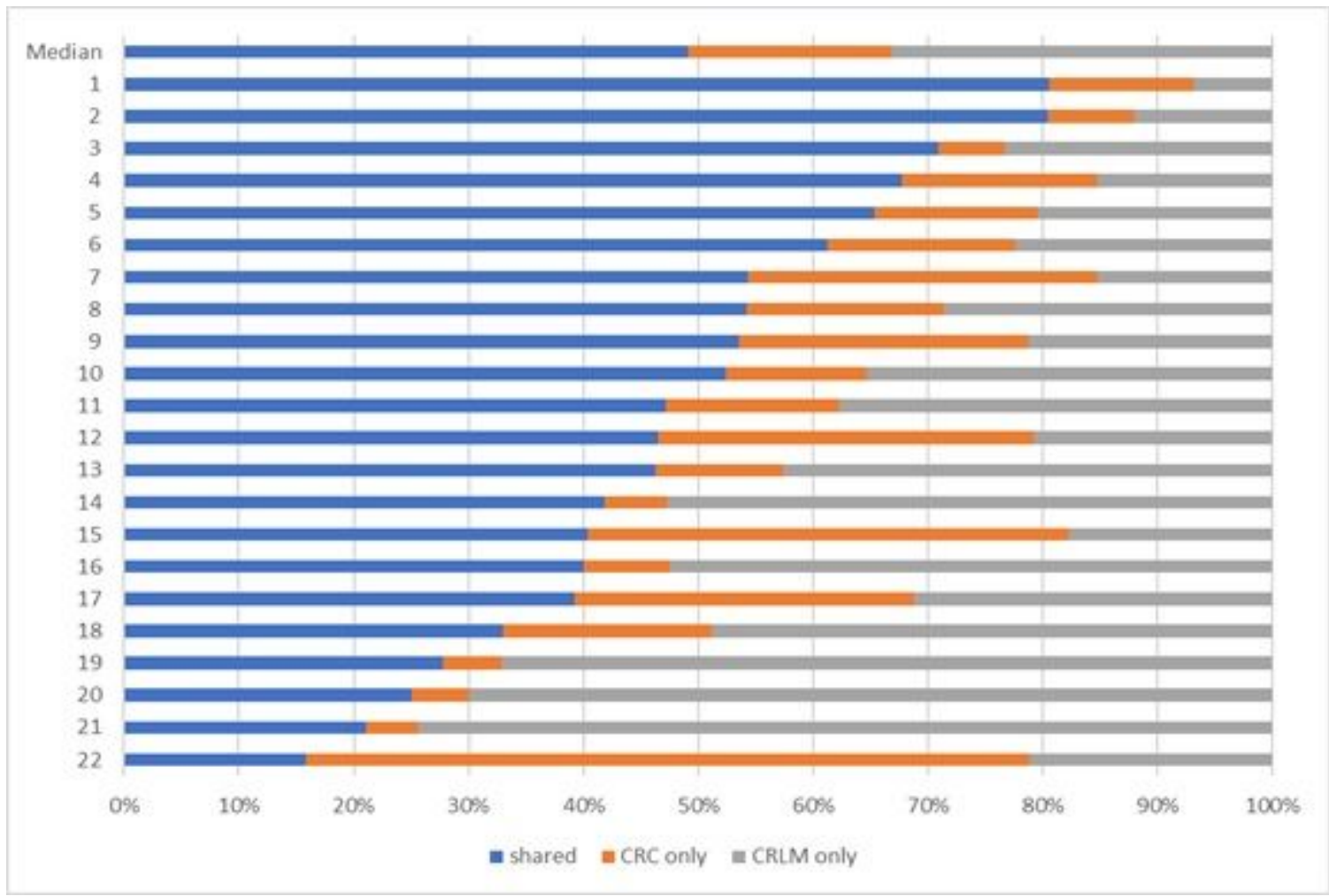

\section{Figure 2}

Concordance of genomic mutations in matched pairs of primary CRC and CRLM

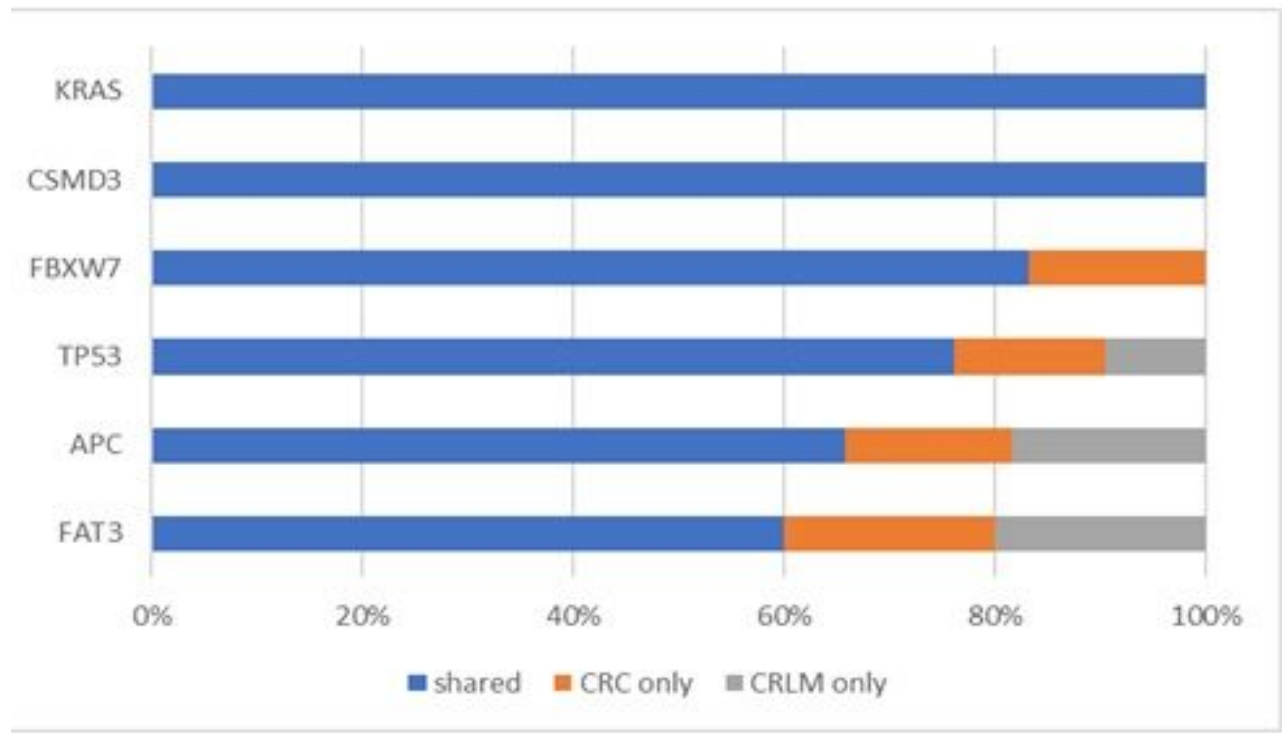

CRC: colorectal cancer CRLM: colorectal liver metastasis

\section{Figure 3}

Concordance of genomic mutations in matched pairs of primary CRC and CRLM 


\section{2 probes}

Liver meta/

Colon cancer $\geqq 1.5$

1794 probes

\section{Colon cancer/ 0 Liver meta \\ normal \\ liver $\geqq 1.0$ \\ 14943 probes \\ normalized \\ value $\geqq 1.0$ \\ 7831 probes}

22

5

\section{Figure 4}

Selection of candidate genes showing significantly higher expression in CRLM than CRC

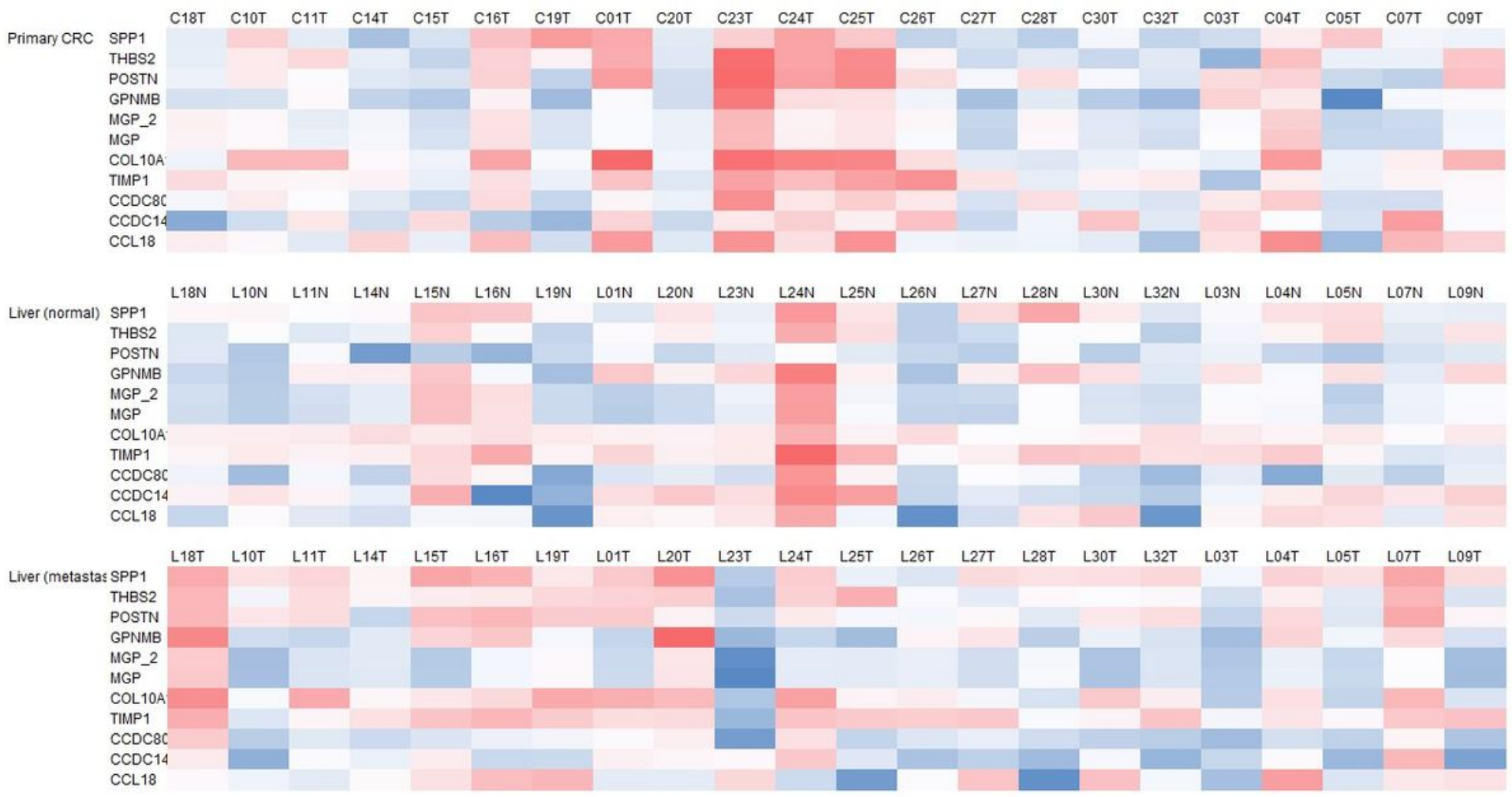


Heat map of the expression profiles from the microarray analysis
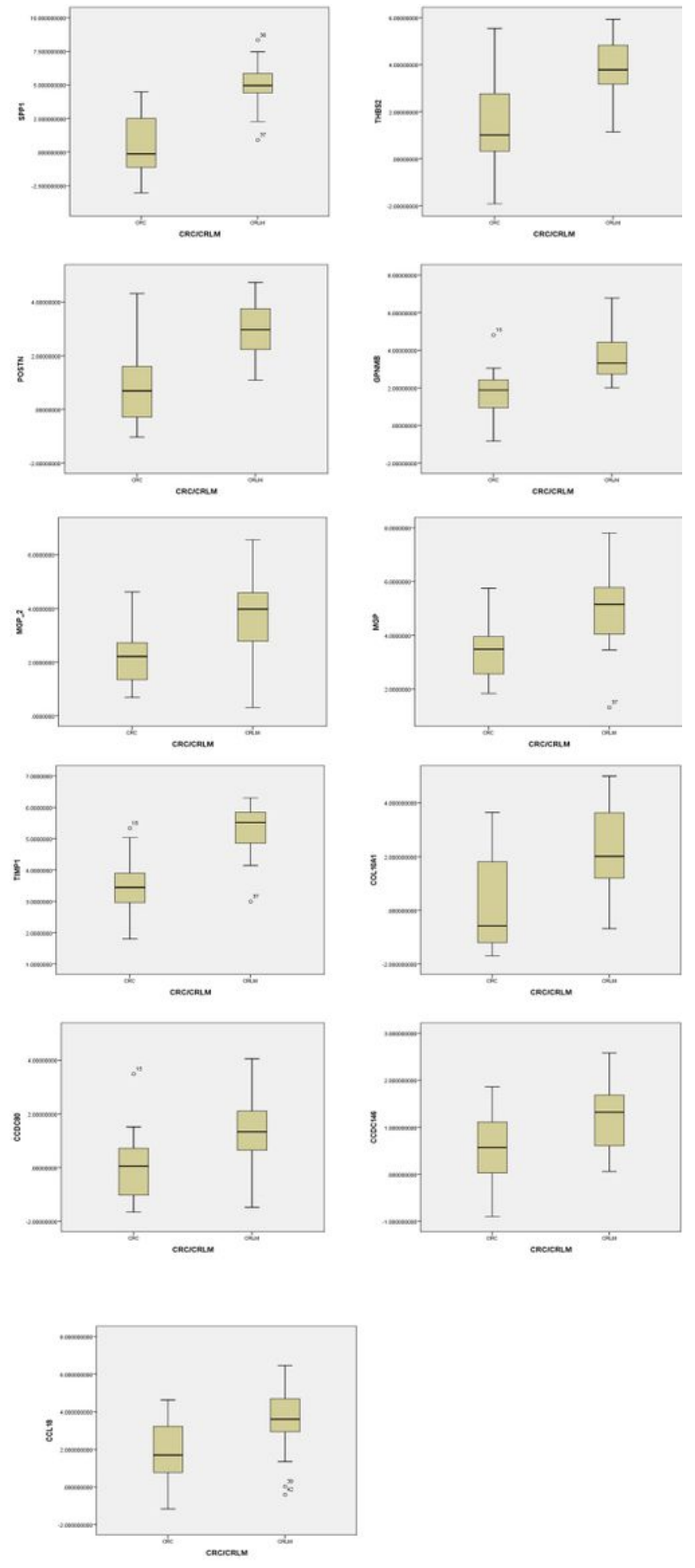

Figure 6

Comparison of gene expression between primary CRC and CRLM 

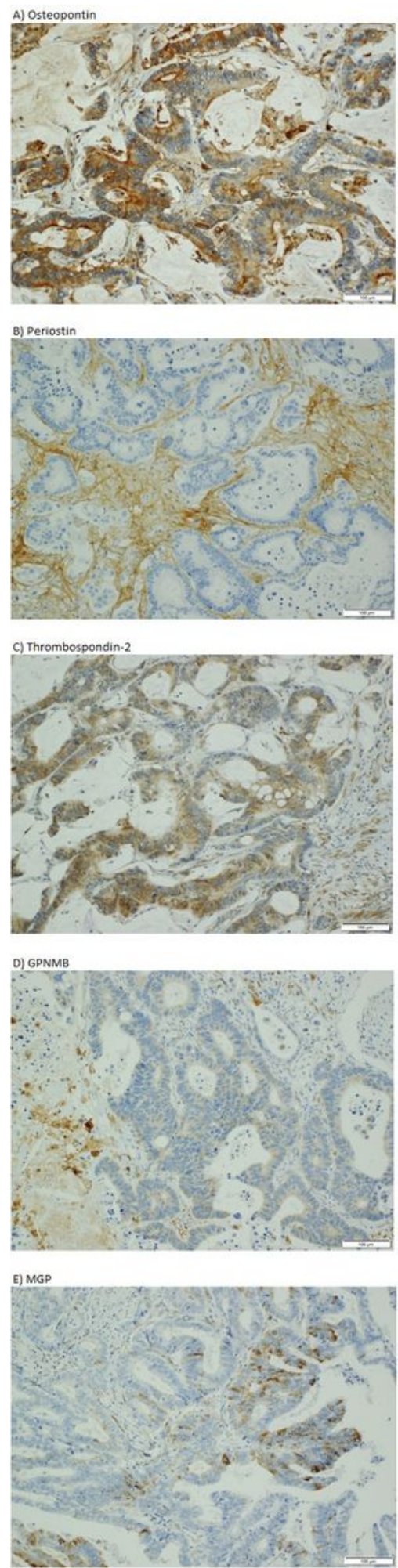

Figure 7

Representative images of immunohistochemical staining for osteopontin, periostin, thrombospondin-2, GPNMB, and MGP in CRLM 